\title{
C-F Bond Activation of a Perfluorinated Ligand Leading to Nucleophilic Fluorination of an Organic Electrophile
}

\author{
Patrick J. Morgan, Magnus W. D. Hanson-Heine, Hayden P. Thomas, Graham C. Saunders,*
} Andrew C. Marr,* and Peter Licence*

Cite This: https://dx.doi.org/10.1021/acs.organomet.0c00176

Read Online

ABSTRACT: We report a fluorine transfer reaction in which fluorine from a perfluorinated ligand undergoes $\mathrm{C}-\mathrm{F}$ bond activation and transfers to an electrophile, resulting in the formation of a new fluorinated product and dimerization of the monodefluorinated complex. Treatment of $\left[\left(\eta^{5}, \kappa_{2} \mathrm{C}-\right.\right.$ $\left.\mathrm{C}_{5} \mathrm{Me}_{4} \mathrm{CH}_{2} \mathrm{C}_{6} \mathrm{~F}_{5} \mathrm{CH}_{2} \mathrm{NC}_{3} \mathrm{H}_{2} \mathrm{NMe}\right)-\mathrm{RhCl}$ ] with the organic electrophile, toluoyl chloride, resulted in the formation of a rhodium(III) metallocycle via $\mathrm{C}-\mathrm{F}$ bond activation assisted defluorinative coupling. Fission of the $\mathrm{C}-$ $\mathrm{F}$ bond liberated nucleophilic fluoride, which converted acyl chloride to acyl fluoride. The overall reaction was monitored using a multivariate analysis approach in real time.

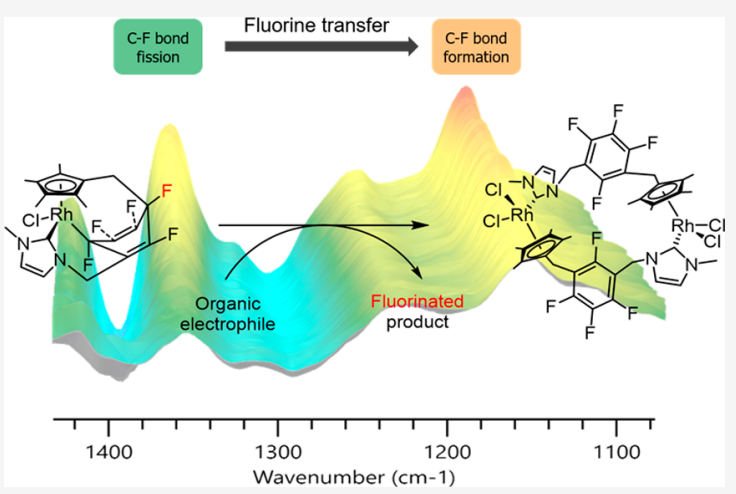

\section{INTRODUCTION}

The activation of carbon-fluorine bonds, once thought to be inert to most chemical manipulations ${ }^{1}$ in part due to high bond dissociation energies, ${ }^{2}$ is gradually becoming synthetically useful and is no longer the insurmountable challenge it once represented. The ability to cleave $\mathrm{C}-\mathrm{F}$ bonds is becoming increasingly important due to our growing awareness of the negative environmental impact of organofluorine, and their persistent nature within the local environment. ${ }^{3-5}$ The potential harmful environmental effects of organofluorine has been highlighted by the bioaccumulation of fluorinated pharmaceuticals $^{6,7}$ or the emission of CFCs and the dangers these hazardous chemicals pose. ${ }^{8}$ One way of dealing with issues related to fluorinated waste is to recycle the fluorine. Some persistent fluorinated pollutants such as $\mathrm{SF}_{6}$ and fluoroform have already undergone valorization through fluorine or trifluoromethane transfer., ${ }^{9}$

The field of $\mathrm{C}-\mathrm{F}$ activation, which started as a series of oneoff transition metal organometallic reactions, ${ }^{11-16}$ has developed in recent years into a rapidly expanding field of research. ${ }^{17-24}$ This expansion has been driven by the need for greener fluorination methodologies (as outlined by the ACS Green Chemistry Institute Pharmaceutical Roundtable) $)^{25,26}$ and the success of fluorinated pharmaceuticals, ${ }^{27,28}$ the growth of which can be partially attributed to the greater accessibility of methodologies available to incorporate a fluorine atom into their molecular structure. New synthetic pathways and strategies are constantly being proposed to prepare fluorinated building blocks, which have been discussed previously. ${ }^{29-37}$
$\mathrm{C}-\mathrm{F}$ activation at a metal center has become a powerful tool for the introduction of new functionality at the site of $\mathrm{C}-\mathrm{F}$ bonds. ${ }^{38-44}$ This process predominantly proceeds via the oxidative addition of the fluoroorganic across the metal center forming a new metal-fluorine bond, followed by the scavenging of fluorine by thermodynamic sinks such as $\mathrm{H}-\mathrm{F}$, $\mathrm{Si}-\mathrm{F}$, or B-F bonds. Transition metal mediated fluorination routes often rely on the formation of a transition metalfluorine bond, ${ }^{4-47}$ which renders fluorine nucleophilic, facilitating its reaction with an electrophile. Both of these routes to activated fluorine rely on the interaction of the fluorinated precursor with the metal center. The generation of activated fluorine distant from the metal center within an organometallic complex is highly unusual, as is the generation of nucleophilic fluorine from the activation of a $\mathrm{C}-\mathrm{F}$ bond. ${ }^{48}$ Ogiwara and Sakai have recently highlighted a metal-based fluorine transfer reaction where benzoyl fluoride is used as a nucleophilic fluorination reagent. Oxidative addition across a palladium center facilitates acyl exchange with anhydrides to yield acyl fluorides and represents a possible use of the fluorinated products produced within this work. ${ }^{49}$ The current focus of our work revolves around the reactivity of complexes bearing a poly- or perfluorinated moiety with organic

Received: March 12, 2020 
a) Silver particle induced cyclometallation.

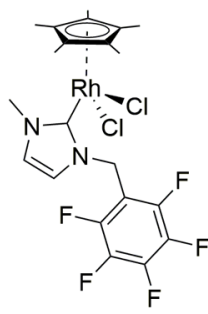
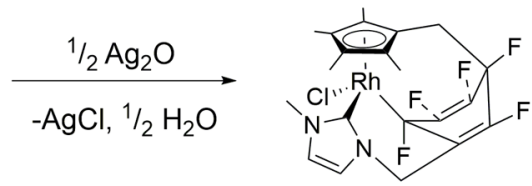

1

b) C-F activation induced fluorine transfer with defluorinative coupling.

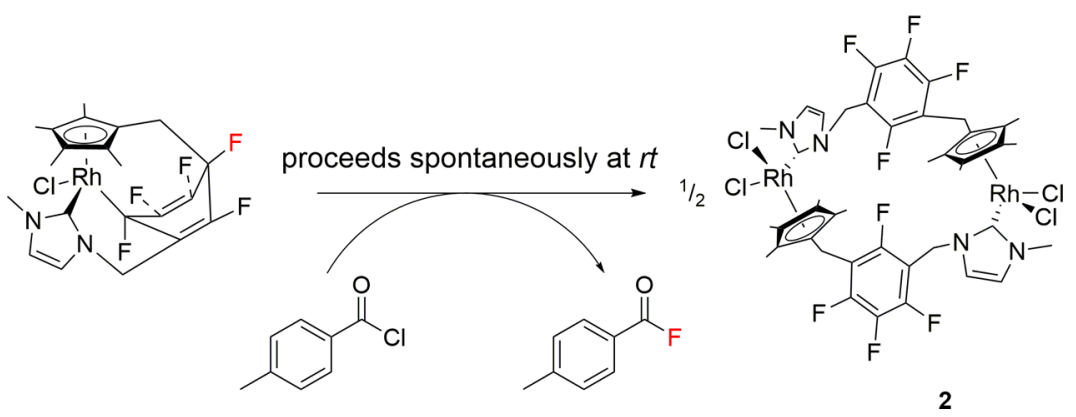

Figure 1. (a) Previous work on silver-particle-induced cyclometalation of rhodium complex, 1. (b) This work on C-F bond activation induced defluorinative coupling, forming 2 , with fluorine transfer to organic electrophiles.

a)

)
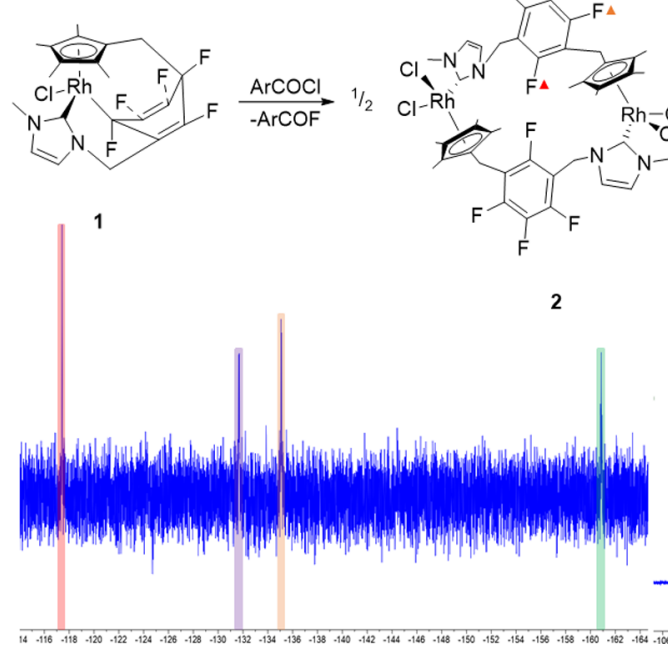

b)

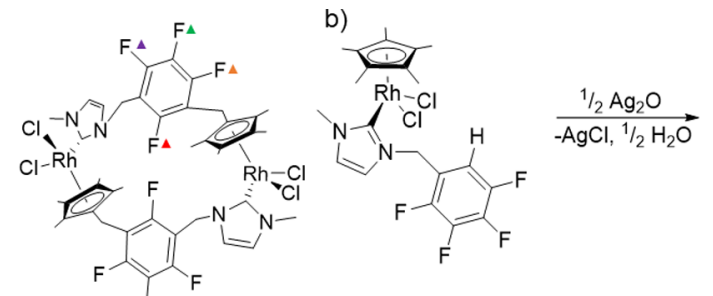

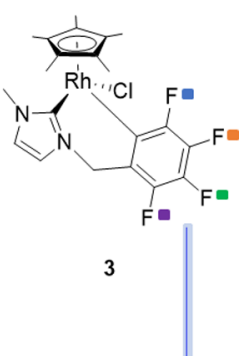

Figure 2. (left, top) Transfer fluorination induced metallocycle formation of 2, including ${ }^{19} \mathrm{~F}$ NMR spectra (left, below) showing four fluorine environments: -117.43 ppm (red), -131.12 ppm (purple), -135.12 ppm (orange), and -160.86 ppm (green). (right, top) Silver-particle-induced ortho-metalation of $\left[\mathrm{Cp} * \mathrm{RhCl}\left(\kappa \mathrm{C}^{2}-\mathrm{MeNC}_{3} \mathrm{H}_{2} \mathrm{NCH}_{2} \mathrm{C}_{6} \mathrm{~F}_{4}\right)\right]$, 3, including ${ }^{19} \mathrm{~F}$ NMR spectra (right, below) showing four fluorine environments: -110.35 ppm (purple), -146.83 ppm (orange), -157.99 ppm (green), and -164.44 ppm (blue).

electrophiles. Reported here is the discovery of a concerted C$\mathrm{F}$ bond activation and formation reaction, where nucleophilic fluorine is generated via the activation of a $\mathrm{C}-\mathrm{F}$ bond from a noninnocent perfluorinated ligand resulting in the fluorination of an electrophile and the formation of a new monodefluorinated bimetallic rhodacycle.

\section{RESULTS AND DISCUSSION}

The transfer of fluorine from a perfluorinated moiety of an organometallic complex onto a nonfluorinated substrate was demonstrated. The reaction was spontaneous and occurred under mild conditions. The reaction occurred via the concurrent $\mathrm{C}-\mathrm{F}$ bond activation, fluorine transfer, and $\mathrm{C}-\mathrm{F}$ bond formation in an external substrate initiated by the treatment of $\left[\left(\eta^{5}, \kappa_{2} \mathrm{C}-\mathrm{C}_{5} \mathrm{Me}_{4} \mathrm{CH}_{2} \mathrm{C}_{6} \mathrm{~F}_{5} \mathrm{CH}_{2} \mathrm{NC}_{3} \mathrm{H}_{2} \mathrm{NMe}\right)-\right.$ $\mathrm{RhCl}],{ }^{50} \mathbf{1}$, with the organic electrophile toluoyl chloride. During the course of the reaction, the fluoride liberated following $\mathrm{C}-\mathrm{F}$ activation reacted with the electrophile toluoyl chloride to give the fluorinated product, toluoyl fluoride, and new complex, 2 (Figure 1). While examples of intramolecular C-F-activated metallacycle formation are known, ${ }^{16,51-57}$ to our knowledge this represents the first account of fluorine transfer via $\mathrm{C}-\mathrm{F}$ activation of a perfluorinated ligand resulting in the fluorination of an external organic substrate, without the formation of deactivated fluorine bonds such as $\mathrm{H}-\mathrm{F}, \mathrm{Si}-\mathrm{F}$, or $\mathrm{B}-\mathrm{F}$, and without producing fluorine-containing waste. 
Treatment of 1 with a 2 fold excess of toluoyl chloride in acetonitrile at room temperature resulted in fluorine transfer from 1 to form toluoyl fluoride, over the course of 1 week. Subsequent NMR analysis resulted in the detection of a new rhodium complex with four distinct fluorine environments within the ${ }^{19} \mathrm{~F} \mathrm{NMR}$, with fluorine resonances of equal integration at $\delta-117.35,-131.84,-135.31$, and -161.06 ppm. The fluorine resonance for toluoyl fluoride at $\delta 17.43$ ppm was in a 1:1 ratio with the newly formed rhodium complex (see Figure S3).

Following our recent observation of $\mathrm{C}-\mathrm{F}$ bond activation induced cyclometalation forming $\left[\mathrm{Cp} * \operatorname{IrCl}\left(\kappa \mathrm{C}^{2}\right.\right.$ $\left.\left.\mathrm{MeNC}_{3} \mathrm{H}_{2} \mathrm{NCH}_{2} \mathrm{C}_{6} \mathrm{~F}_{4}\right)\right],{ }^{51}$ it was initially thought that a similar process was occurring for the rhodium analogue, where $\mathrm{C}-\mathrm{F}$ bond activation at the $\mathrm{C}-\mathrm{F}$ bond $\alpha$ to the metal center, followed by rearomatization of the phenyl ring resulted in the formation of $\left[\mathrm{Cp} * \mathrm{RhCl}\left(\kappa \mathrm{C}^{2}-\mathrm{MeNC}_{3} \mathrm{H}_{2} \mathrm{NCH}_{2} \mathrm{C}_{6} \mathrm{~F}_{4}\right)\right], 3$ (Figure 2). However, the ${ }^{19} \mathrm{~F}$ NMR spectral signature of the new four-fluorine-environment rhodium complex observed upon reaction with toluoyl fluoride (Figure $2 \mathrm{a}$ ) differed from that observed for $\left[\mathrm{Cp} * \operatorname{IrCl}\left(\kappa \mathrm{C}^{2}-\mathrm{MeNC}_{3} \mathrm{H}_{2} \mathrm{NCH}_{2} \mathrm{C}_{6} \mathrm{~F}_{4}\right)\right]$. This deviation between the ${ }^{19} \mathrm{~F}$ NMR spectrum for the new fourfluorine-environment rhodium complex and the iridium orthometalated complex was larger than expected if $\mathrm{C}-\mathrm{F}$ bond activation induced cyclometalation of the rhodium species had occurred. Subsequent synthesis and characterization of $\left[\mathrm{Cp} * \mathrm{RhCl}\left(\kappa \mathrm{C}^{2}-\mathrm{MeNC}_{3} \mathrm{H}_{2} \mathrm{NCH}_{2} \mathrm{C}_{6} \mathrm{~F}_{4}\right)\right], 3$ (Figure 2b), proved that 3 was not the identity of the new complex observed. Therefore, further complementary studies were required in order to deduce the structure of the new rhodium complex, 2.

The structure of $\mathbf{2}$ was solved by single-crystal X-ray diffraction (Figure 3). Work up by elution of the reaction

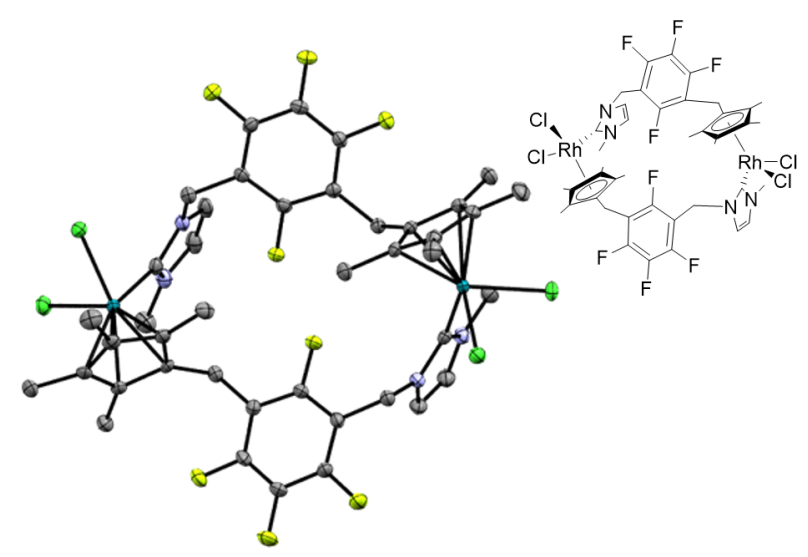

Figure 3. Molecular structure of 2. Thermal ellipsoids for the anisotropic displacement parameters represent 50\% probability. Hydrogen atoms and solvent molecules have been omitted for clarity. Selected bond distances $(\AA)$ and angles (deg) given in Table S3.

mixture with cold ether resulted in the separation of the metal complex and organic product. Slow evaporation of a saturated DCM solution of $\mathbf{2}$ resulted in the formation of single crystals. 2 comprises a bimetallic metallocycle in which the methylene group of the $\mathrm{Cp}^{*}$ ligand of one complex is attached to the partially fluorinated phenyl ring of the substituted NHC of another molecule at the site of $\mathrm{C}-\mathrm{F}$ activation.

Transfer fluorination resulting in the formation of $\mathbf{2}$ and a fluorinated product was not restricted to the use of toluoyl chloride as a substrate. The fluorination of additional substrates and functional groups has been summarized in Table 1. As a 10-fold excess of the electrophile was used, conversion has been calculated with respect to the formation of 2 , which is in a roughly $1: 1$ ratio with the fluorinated organic product, and the ${ }^{19} \mathrm{~F}$ NMR yield of the product against an internal standard. Of particular interest was the fluorination of anhydrides upon treatment with 1 resulting in the formation of acyl fluorides. Transfer fluorination occurred more rapidly using anhydrides as the substrate compared to acyl chlorides, with detection of the fluorinated product after only $10 \mathrm{~min}$ (entries 1-3). Acetic anhydride rapidly underwent fluorination resulting in $11 \%$ yield of acetyl fluoride and a $12.5 \%$ conversion to $\mathbf{2}$ over $10 \mathrm{~min}$. Benzoic anhydride showed similar reactivity with $47.7 \%$ yield of the fluorinated product after $30 \mathrm{~min}$, with $50 \%$ conversion from 1 to 2 observed (Table 1, entry 2). Butyric anhydride underwent fluorination to butyryl fluoride over the course of $20 \mathrm{~h}$ resulting in $28.3 \%$ conversion of 2 (Table 1, entry 3 ). The reactivity of anhydrides is in contrast to acyl chlorides, for which the fluorinated product was identified after $4 \mathrm{~h}$ leading to $18 \%$ conversion of toluoyl fluoride after 72 h (Table 1, entry 4). Similar lower activity was observed for benzoyl chloride (Table 1 , entry 5 ). Taking toluoyl chloride as an example, the rate of formation of toluoyl fluoride decreased after $20 \mathrm{~h}$. Monitoring of the reaction showed $12.5 \%$ yield after 20 h with $22.8 \%$ yield of toluoyl fluoride after 5 days, clearly showing a reduction in the rate of formation of the fluorinated product over time. After 5 days, 1 was not observed in solution. As the concentration of $\mathbf{1}$ decreases in solution over time, the rate of formation of the fluorinated product and 2 also decreases (Figure S11). This is consistent with the rate of dimer (2) formation becoming increasingly limited by the concentration of $\mathbf{1}$. Other transfer fluorination attempts are listed in Table S1.

In situ monitoring of the reaction (Table 1, entry 1) was carried out using the in situ infrared technique ReactIR. ReactIR enables the measurement of reaction profiles and trends, allowing for changes in the composition of a reaction to be monitored in real time. The IR probe was added to a Schlenk tube containing 1, acetic anhydride and dry, degassed acetonitrile under a nitrogen atmosphere. During the course of the experiment, the $\mathrm{C}-\mathrm{O}$ band at $1268 \mathrm{~cm}^{-1}$, corresponding to acetic anhydride substrate, and a $\mathrm{C}-\mathrm{F}$ band of 1 at $1386 \mathrm{~cm}^{-1}$ reduced in intensity. Meanwhile, a new $\mathrm{C}-\mathrm{F}$ band corresponding to acyl fluorides $\left(1346 \mathrm{~cm}^{-1}\right)$ grew in intensity, proportional to the loss of the C-F bond of $\mathbf{1}$ (Figure 4, left). This correlation shows that the fluorine incorporated within the acyl fluoride product comes from the perfluorinated ligand of 1 , confirming transfer fluorination between a perfluorinated moiety and organic substrate is occurring. The use of ReactIR as an in situ monitoring technique for this reaction confirms the observation of transfer of the fluoride from one substrate to the other. Similar reactivity was observed for benzoic anhydride. The time scale of reactivity for toluoyl chloride was too long for in situ monitoring to be accessible.

Intermolecular defluorinative coupling results in the formation of 2, liberating nucleophilic fluoride via $\mathrm{C}-\mathrm{F}$ activation, which undergoes nucleophilic attack on the organic electrophile. The aromatization of the polyfluorocyclohexa-1,4diene substituent could be key to the formation of 2 , as the conformational change caused by the conversion of the ring to planar may pull one of the ligands ( $\mathrm{Cp}^{*}$ or $\mathrm{NHC}$ ) from the metal. The fission of the $\mathrm{Rh}-\mathrm{Cp}$ * bond of 1 would lead to a 
Table 1. Transfer Fluorination of Organic Substrates by Fluorine Transfer ${ }^{a}$

Entry

${ }^{a}$ Reaction conditions: $1(0.0056 \mathrm{mmol})$, substrate $(0.056 \mathrm{mmol})$ in $\mathrm{CD}_{3} \mathrm{CN}(0.5 \mathrm{~mL})$ under argon at room temperature. ${ }^{b}$ Determined by ${ }^{19} \mathrm{~F}$ NMR spectroscopy using $\alpha, \alpha, \alpha$-trifluorotoluene as internal standard.

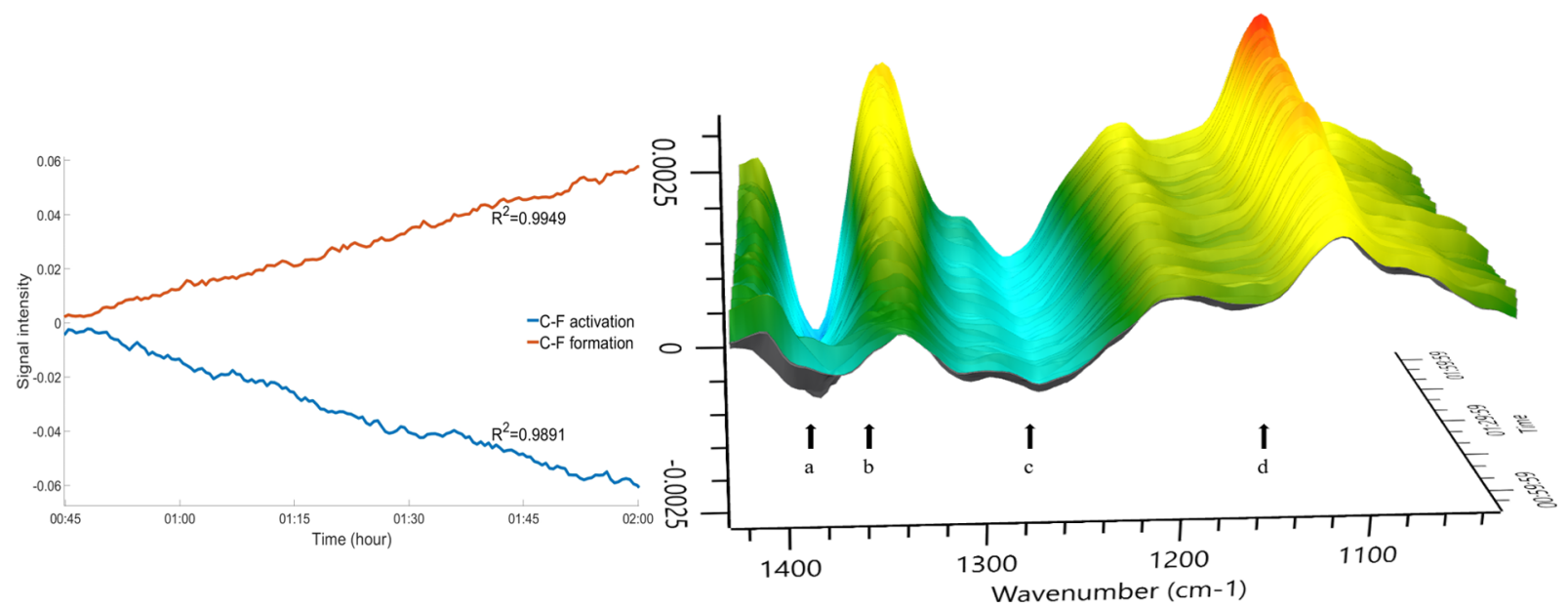

Figure 4. (left) Plot of the rate of change of $\mathrm{C}-\mathrm{F}$ bond fission $\left(1386 \mathrm{~cm}^{-1}\right)$ and $\mathrm{C}-\mathrm{F}$ bond formation $\left(1346 \mathrm{~cm}^{-1}\right)$ over the course of the reaction highlighting the correlation between the two linear regression plots. (right) $3 \mathrm{D}$ surface plot for reaction of $1(20 \mathrm{mg})$ with acetic anhydride $(35 \mu \mathrm{L})$ in acetonitrile $(5 \mathrm{~mL})$. The peaks associated with the solvent, acetic anhydride, and $\mathbf{1}$ have been subtracted from the plot to allow for changes over time to be observed. The changes that occur over time include (from left to right) (a) the cleavage of a C-F bond of 1 at $1386 \mathrm{~cm}^{-1}$, (b) formation of a new $\mathrm{C}-\mathrm{F}(\mathrm{COF})$ bond at $1346 \mathrm{~cm}^{-1}$, (c) cleavage of a $\mathrm{C}-\mathrm{O}$ bond from acetic anhydride at $1268 \mathrm{~cm}^{-1}$, and $(\mathrm{d})$ formation of a new $\mathrm{C}-\mathrm{O}(\mathrm{H})$ group as byproduct at $1130 \mathrm{~cm}^{-1}$.

zwitterionic fragment, which when combined with a second fragment may form 2 (Figure 5a). Conversely removal of the NHC could form a 16-electron neutral intermediate, which at first glance would appear more likely (Figure 5b).

While metal-Cp* bonds may be difficult to cleave thermally, ${ }^{58}$ photoinitiated $\mathrm{M}-\mathrm{Cp}^{(*)}$ bond migration is a known process. ${ }^{58-60}$ To investigate whether photoactivation may be occurring, toluoyl chloride and 1 were exposed to highintensity filtered UV (308 and $360 \mathrm{~nm}$ ) in a quartz reactor, under inert, dry conditions. Sampling of the reaction over time showed the rapid formation of both toluoyl fluoride and 2 within $30 \mathrm{~min}$. UV/vis analysis of samples during this time showed the decrease in intensity of the absorption peak at 328 $\mathrm{nm}$, the blueshift of the maximum to $252 \mathrm{~nm}$ (associated with 1), and the growth of a band at $408 \mathrm{~nm}$, representing 2 (Figure 6). ${ }^{19} \mathrm{~F}$ NMR analysis of the reaction mixture shows the formation of toluoyl fluoride with $40 \%$ conversion after 30 min. The quantity of fluorinated product and $\mathbf{2}$ formed were in a $1: 1$ ratio, consistent with the thermal result.
Brubaker and Lee noted in their work on photochemical Cp exchange $^{59}$ that while photolysis of the metal-Cp bond readily occurred, thermal exchange occurred slowly resulting in roughly $10 \%$ formation of the exchange products after 1 week. Given that photoexcitation of toluoyl chloride and $\mathbf{1}$ gives a $40 \%$ conversion to toluoyl fluoride over $30 \mathrm{~min}$ compared to the thermal route which initially gave $13 \%$ conversion to toluoyl fluoride over 2 weeks, we propose that a similar process is occurring. This supports a mechanism leading to transfer fluorination and the formation of 2 via $\mathrm{Rh}-$ $\mathrm{Cp}^{*}$ bond cleavage (Figure 5a). However, photoactivation of the $\mathrm{Rh}-\mathrm{NHC}$ bond cannot be ruled out.

Density functional theory (DFT) geometry optimizations, NMR shifts, and energy and electron density calculations were performed for $\mathbf{1}$ and $\mathbf{2}$ (see Supporting Information section 1.6 for calculation details). The calculated fluorine interaction energies (Figure 7) indicated that fluorine atoms attached to the carbon atoms in $\mathbf{1}$ that are displaced away from the plane of the ring (bonds 1 and 4) have interaction energies ca. $50 \mathrm{~kJ} /$ mol lower than those of the fluorine atoms attached to the 
a)

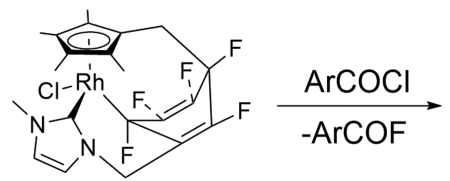

1

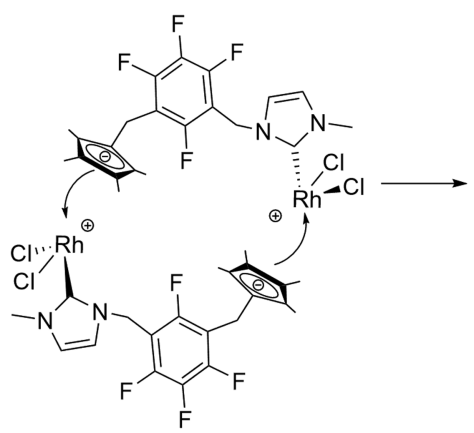

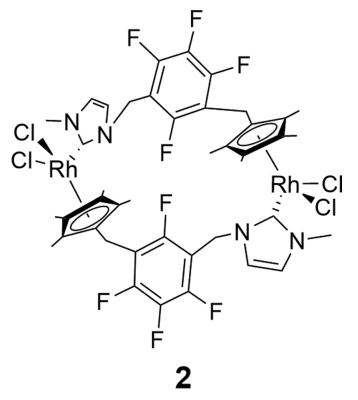

b)

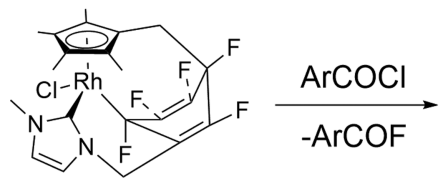

1
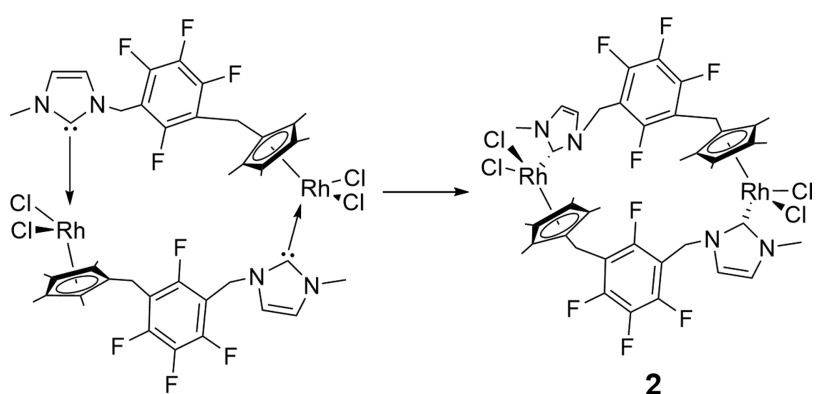

Figure 5. Reaction of 1 with toluoyl chloride (a) showing dimerization of zwitterion following fission of the $\mathrm{Rh}-\mathrm{Cp}^{*}$ bond or (b) showing recombination of free NHC to the neutral 16-electron Rh complex, resulting in the formation of 2 .

a)

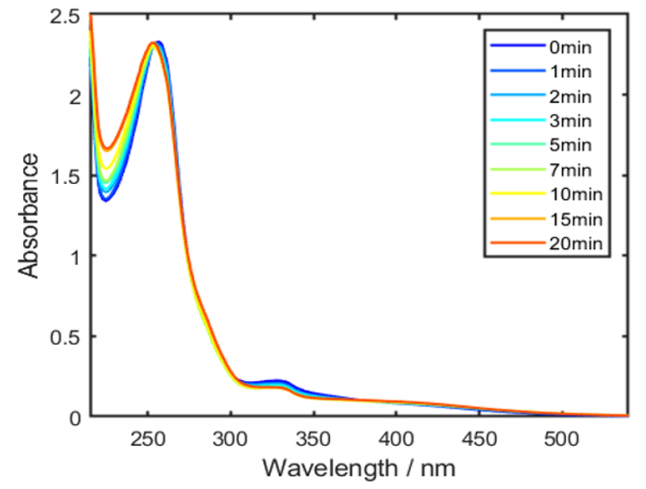

c)

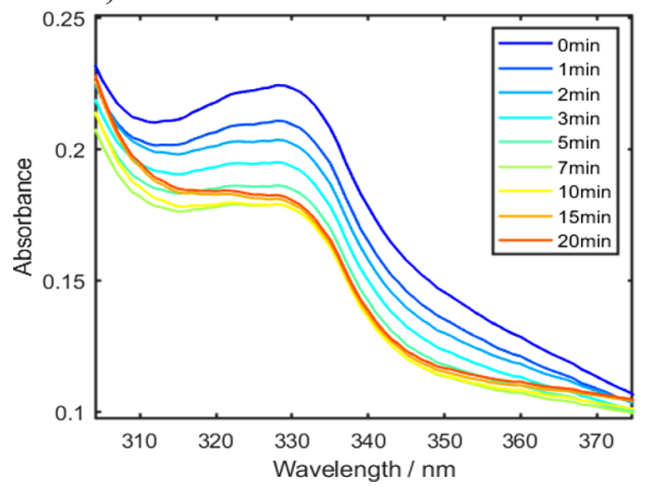

b)

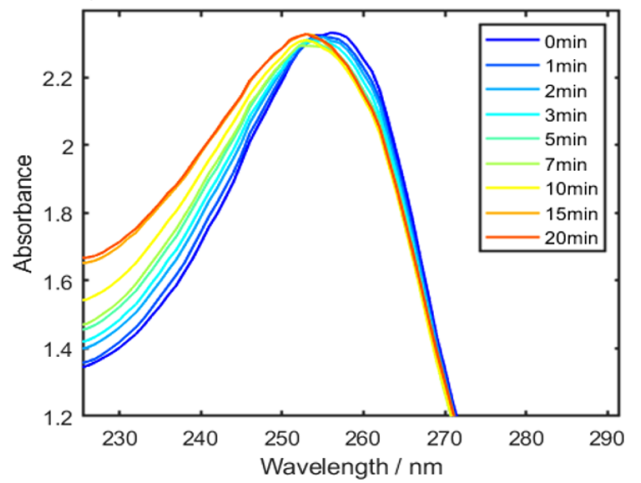

d)

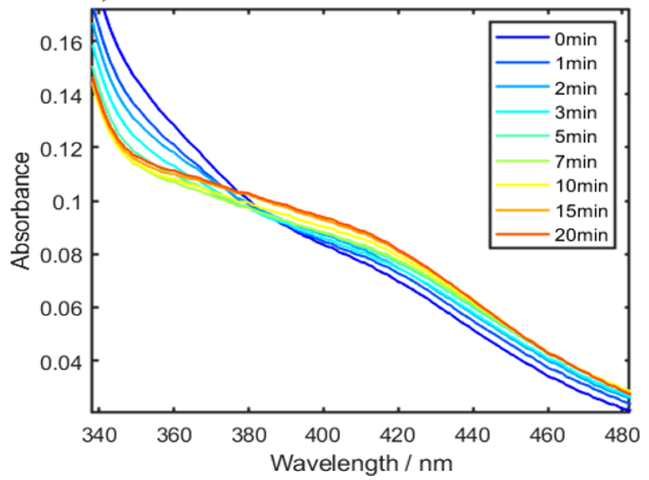

Figure 6. (a) UV/vis plot of the photolysis of 1 with toluoyl chloride over time. (b) Shift of maximum peak to 252 nm. (c) Reduction in intensity of $330 \mathrm{~nm}$ band. (d) Appearance of a new band at $395 \mathrm{~nm}$.

more coplanar carbon atoms (bonds 2, 3, and 5). The fluorine attached to the carbon atom connected to the $\mathrm{Cp}^{*}$ ring (bond 1) has the weakest calculated interaction overall, ca. $6 \mathrm{~kJ} / \mathrm{mol}$ lower than the fluorine attached to the metal bound carbon (bond 4). The ${ }^{19} \mathrm{~F}$ chemical shifts for 1 have also been calculated for the optimized geometry (Figure S24), which align closely with those observed experimentally. ${ }^{50}$ Natural population analysis was used to calculate the occupancy and charge distribution of electrons for each fluorine atom within 1. The fluorine atoms displaced away from the plane of the 


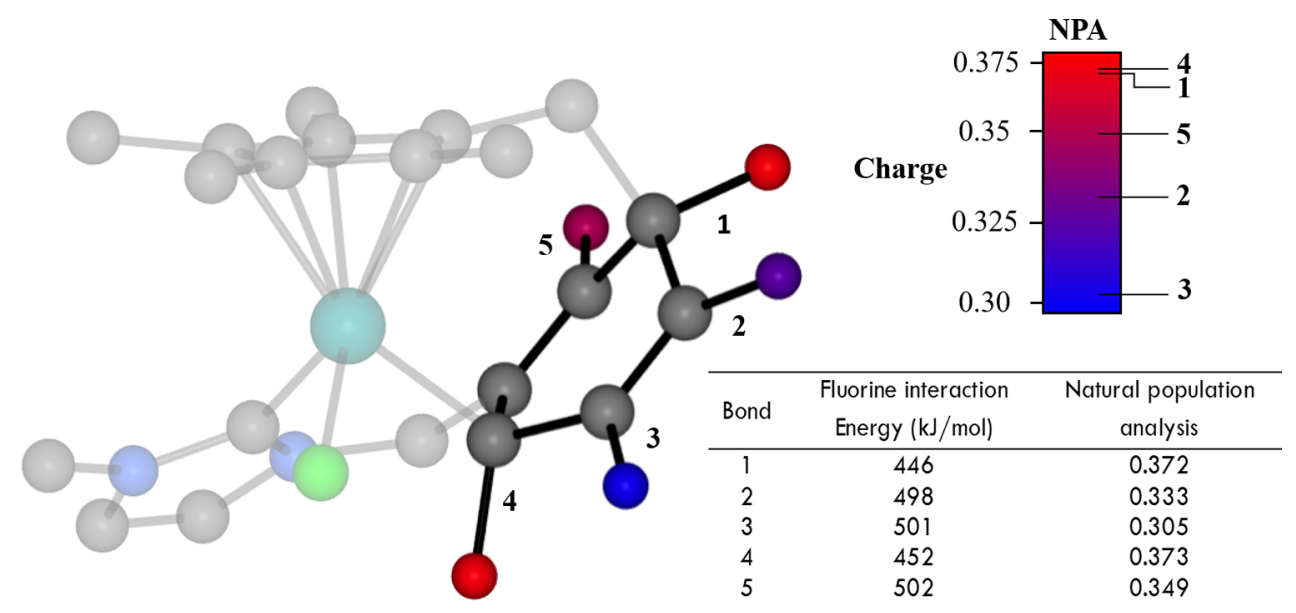

Figure 7. Optimized geometry of 1 with the polyfluorocyclohexadiene region highlighted. The color of the fluorine atoms has been changed to correspond with their natural population analysis (NPA) as given in the gradient scale (top right). The calculated fluorine atom interaction energies and the relative charge from natural population analysis for bonds $1-5$ are given in the table (bottom right). Geometries were calculated at the PBE0/6-31G(d)/LANL2DZ level of theory. Energies and natural populations were calculated at the PBE0/6-311++G(d,p)/SRSC level of theory.

ring (bonds 1 and 4) have the most negative overall atom charges. Therefore, these fluorine atoms can be considered more nucleophilic due to the greater electron density found on the atom.

The ReactIR data, the crystal structure of 2 , the theoretical calculations, and the ${ }^{19} \mathrm{~F}$ NMR tell a coherent story about $\mathrm{C}-\mathrm{F}$ bond activation and fluorine dissociation. The reactive $\mathrm{C}-\mathrm{F}$ bond in $\mathbf{1}$ has the lowest calculated fluorine interaction energy, one of the highest fluorine atom charges (from NPA), and the most upfield chemical shift in the ${ }^{19} \mathrm{~F}$ NMR. The results reveal the activation of fluorine within a perfluorinated moiety, rendering it nucleophilic. Multivariate analysis confirms fluorine transfer from the perfluorinated ligand of $\mathbf{1}$ to the organic electrophiles, resulting in the formation of the fluorinated product and 2 .

\section{CONCLUSIONS}

In conclusion, we report the reactivity of $\left[\left(\eta^{5}, \kappa_{2} \mathrm{C}-\right.\right.$ $\left.\left.\mathrm{C}_{5} \mathrm{Me}_{4} \mathrm{CH}_{2} \mathrm{C}_{6} \mathrm{~F}_{5} \mathrm{CH}_{2} \mathrm{NC}_{3} \mathrm{H}_{2} \mathrm{NMe}\right)-\mathrm{RhCl}\right]$, 1, to form dirhodium species 2 upon treatment with organic electrophiles. C$\mathrm{F}$ bond activation was followed by concurrent rhodacycle formation resulting in up to $1: 1$ formation of 2 and fluorinated products. Photoexcitation of $\mathbf{1}$ with toluoyl chloride resulted in the rapid formation of $\mathbf{2}$ and toluoyl fluoride, and on the basis of this, we propose a mechanism for the formation of $\mathbf{2}$ involving $\mathrm{Cp}^{*}$ migration. The nucleophilic fluorine was remarkable, as it arose from a perfluorinated ligand's $\mathrm{C}-\mathrm{F}$ bond and not from fluorine attached to the metal center. The formation of $\mathbf{1}$ involved nucleophilic attack of a perfluorinated aryl by a strong nucleophile generate from the deprotonation of $\mathrm{Cp}^{*}$ (Figure $1 \mathrm{~b}$ ), and this appears to have rendered the C$\mathrm{F}$ bond unusually electron-rich. Fluorine transfer or shuttling that results in the formation of a new $\mathrm{C}-\mathrm{F}$ bond is very rare. It is therefore important to understand the chemical nature of fluorine in $\mathbf{1}$ in order to harness the synthetic potential of this reaction. Toward this end, computational fluorine interaction energies and natural population analysis gave some insight into the reactivity of parent complex $\mathbf{1}$, and this provided a first understanding of the environment required to initiate a nucleophilic transfer fluorination.

\section{EXPERIMENTAL SECTION}

General Information. NMR spectral analysis was carried out using a Bruker Ascend 400 spectrometer $(400 \mathrm{MHz})$ and Bruker Ascend 500 spectrometer $(500 \mathrm{MHz})$ at room temperature $(\approx 300$ $\mathrm{K}) .{ }^{1} \mathrm{H}$ and ${ }^{13} \mathrm{C}$ NMR spectra were calibrated to the corresponding solvent signals $\left(\mathrm{CDCl}_{3}: 7.26 \mathrm{ppm}\right.$ for ${ }^{1} \mathrm{H}, 77.16 \mathrm{ppm}$ for $\left.{ }^{13} \mathrm{C}\right)$. The ${ }^{19} \mathrm{~F}$ NMR spectra were calibrated by an internal method of the NMR. The chemical shifts are reported in ppm, and coupling constants are given in Hz. Electrospray mass spectra were recorded on a Bruker micrOTOF II with Agilent technologies 1200 Infinity Series mass spectrometer. $\mathrm{RhCp}^{*}\left(\mathrm{Cl}_{2}\right)\left(\mathrm{F}_{5} \mathrm{Bzmim}\right)$ and $\mathbf{1}$ were synthesized as previously described. ${ }^{50,61,62}$ 3-Methyl-1-(3,4,5,6-tetrafluorobenzyl)imidazolium bromide was synthesized using a similar procedure which has previously been described. ${ }^{61}$ 1-Methylimidazole, silver oxide, toluoyl chloride, benzoyl chloride, benzoic anhydride, and butyric anhydride were purchased from Sigma-Aldrich (Merck). $\left[\mathrm{RhCp} * \mathrm{Cl}_{2}\right]_{2}$ was purchased from Alfa Aesar. Acetic anhydride was purchased from VWR. All solvents were purified, degassed, and dried before use.

Procedure for Synthesis of 2. Dichloromethane $(5 \mathrm{~mL})$ was added to a flask containing $\mathbf{1}(25 \mathrm{mg}, 0.046 \mathrm{mmol})$. Once dissolved, toluoyl chloride $(0.10 \mathrm{mmol}, 2$ equiv) was added, and the stirring was continued for 1 week. The reaction mixture was removed from the glovebox, and the solvent was removed in vacuo resulting in an orange crystalline powder and an orange oil. $\mathrm{CDCl}_{3}(0.5 \mathrm{~mL})$ was added, and the solution was transferred to a Young's valve NMR tube under argon. Analysis of the ${ }^{19} \mathrm{~F}$ NMR showed up to $30 \%$ conversion of $\mathbf{1}$ to 2. Toluoyl fluoride was extracted with ether, and $\mathbf{2}$ was recrystallized from a saturated solution of dichloromethane. Isolated yield: $3.5 \mathrm{mg}$ (13.7\% yield). ${ }^{1} \mathrm{H}$ NMR $\left(400 \mathrm{MHz}\right.$, chloroform- $\left.d_{1}\right): \delta 7.71\left(\mathrm{~d}, J_{\mathrm{HH}}=\right.$ $3.3 \mathrm{~Hz}, \mathrm{HCCH}, 1 \mathrm{H}), 7.70\left(\mathrm{~d}, J_{\mathrm{HH}}=3.3 \mathrm{~Hz}, \mathrm{HCCH}^{\prime}, 1 \mathrm{H}\right), 7.54(\mathrm{~d}$, $\left.J_{\mathrm{HH}}=3.3 \mathrm{~Hz}, \mathrm{HCCH}, 1 \mathrm{H}\right), 7.53\left(\mathrm{~d}, J_{\mathrm{HH}}=3.3 \mathrm{~Hz}, \mathrm{HCCH}^{\prime}, 1 \mathrm{H}\right), 5.82$ $\left(\mathrm{d}, \mathrm{J}_{\mathrm{HH}}=16.5 \mathrm{~Hz}, \mathrm{CH}_{2}, 2 \mathrm{H}\right), 5.56\left(\mathrm{~d}, J_{\mathrm{HH}}=16.2 \mathrm{~Hz}, \mathrm{CH}_{2}, 2 \mathrm{H}\right), 4.05$ (s, $\left.\mathrm{CH}_{3}, 6 \mathrm{H}\right), 1.87\left(\mathrm{~s}, \mathrm{C}_{5}-\mathrm{CH}_{2}, 4 \mathrm{H}\right), 1.77\left(\mathrm{~s}, \mathrm{C}_{5}-\mathrm{CH}_{3}, 6 \mathrm{H}\right), 1.40(\mathrm{~s}$, $\left.\mathrm{C}_{5}-\mathrm{CH}_{3}, 6 \mathrm{H}\right), 1.25\left(\mathrm{~s}, \mathrm{C}_{5}-\mathrm{CH}_{3}, 6 \mathrm{H}\right), 0.92\left(\mathrm{~s}, \mathrm{C}_{5}-\mathrm{CH}_{3}, 6 \mathrm{H}\right) .{ }^{19} \mathrm{~F}$ NMR (376 MHz, chloroform- $\left.d_{1}\right): \delta-117.43\left(\mathrm{~s}, \mathrm{C}_{6}-F, 1 \mathrm{~F}\right),-131.12$ $\left(\mathrm{d}, J_{\mathrm{FF}}=19.9 \mathrm{~Hz}, \mathrm{C}_{6}-F, 1 \mathrm{~F}\right),-135.12\left(\mathrm{~d}, J_{\mathrm{FF}}=20.9 \mathrm{~Hz}, \mathrm{C}_{6}-F, 1 \mathrm{~F}\right)$, $-160.86\left(\mathrm{t}, J_{\mathrm{FF}}=22.8 \mathrm{~Hz}, \mathrm{C}_{6}-F, 1 \mathrm{~F}\right)$. MS (ESI) of 2: theoretical for $\mathrm{C}_{21} \mathrm{H}_{21} \mathrm{Cl}_{1} \mathrm{~F}_{4} \mathrm{~N}_{2} \mathrm{Rh}[\mathrm{M} / 2-\mathrm{Cl}]^{+}$515.0384. Found $[\mathrm{M} / 2-\mathrm{Cl}]^{+}$ 515.0389. Theoretical for $\mathrm{C}_{42} \mathrm{H}_{42} \mathrm{Cl}_{3} \mathrm{~F}_{8} \mathrm{~N}_{4} \mathrm{Rh}_{2}[\mathrm{M}-\mathrm{Cl}]^{+} 1065.0457$. Found $[\mathrm{M}-\mathrm{Cl}]^{+}$1065.0445: The formation of toluoyl fluoride was also identified: $1 \mathrm{mg}$ ( $13.3 \%$ yield; $97 \%$ conversion vs $0.003 \mathrm{mmol}$ of 2 formed \{Figure S3\}). ${ }^{1} \mathrm{H}$ NMR (400 MHz, chloroform- $\left.d_{1}\right): \delta 7.99$ $\left(\mathrm{d}, J_{\mathrm{HH}}=8.1 \mathrm{~Hz}, \mathrm{C}_{6}-\mathrm{H}, 2 \mathrm{H}\right), \delta 7.27\left(\mathrm{~d}, J_{\mathrm{HH}}=8.1 \mathrm{~Hz}, \mathrm{C}_{6}-\mathrm{H}, 2 \mathrm{H}\right)$, $2.43(\mathrm{~s}, \mathrm{Me}, 3 \mathrm{H}) .{ }^{19} \mathrm{~F}$ NMR (376 MHz, $d_{1}$-chloroform): $\delta 17.30(\mathrm{~s}$, 
$1 \mathrm{~F}, \mathrm{COF})$. MS (ESI) of toluoyl fluoride: theoretical $[\mathrm{M}-\mathrm{F}]^{+}$ $\left[\mathrm{C}_{8} \mathrm{H}_{7} \mathrm{O}\right]^{+}$119.0497. Found $\left[\mathrm{C}_{8} \mathrm{H}_{7} \mathrm{O}\right]^{+} 119.0498$.

General Procedure for the Fluorine Transfer between 1 and Organic Electrophiles. The organic electrophile $(0.056 \mathrm{mmol})$ was added to a Young's tap NMR tube containing $1(3 \mathrm{mg}, 0.0056 \mathrm{mmol})$ and dry, degassed $\mathrm{CD}_{3} \mathrm{CN}(0.5 \mathrm{~mL})$ with $\alpha, \alpha, \alpha$-trifluorotoluene (1 $\mu \mathrm{L})$ under argon. The contents of the tube were shaken, and the reaction was monitored via ${ }^{19} \mathrm{~F}$ NMR over time. The conversion and formation of the fluorinated product are highlighted in Table S1; the substrate specific experimental is given below (sections 1.4.2-1.4.11 of the Supporting Information). Due to the 10 equiv of substrate added ${ }^{1} \mathrm{H}$ NMR analysis of products proved difficult in some cases due to overlapping signals. Products have been assigned using ${ }^{19} \mathrm{~F}$ NMR, referenced against literature precedent, where available.

Acetic Anhydride. The acetyl fluoride product was formed using the general method (section 1.4.1 of the Supporting Information). Acetic anhydride $(6 \mathrm{mg}, 0.056 \mathrm{mmol})$ was added to a Young's tap NMR tube containing 1 (3 mg, $0.0056 \mathrm{mmol})$ in dry, degassed $\mathrm{CD}_{3} \mathrm{CN}(0.5 \mathrm{~mL})$ with $\alpha, \alpha, \alpha$-trifluorotoluene $(1 \mu \mathrm{L})$ under argon. The contents of the tube were shaken and the reaction monitored via ${ }^{19} \mathrm{~F}$ NMR over time. ${ }^{19} \mathrm{~F}$ NMR yield versus the internal standard after $10 \mathrm{~min}: 11.2 \% .{ }^{19} \mathrm{~F}$ NMR $\left(376 \mathrm{MHz}, \mathrm{ACN}-d_{3}\right): \delta 48.91\left(\mathrm{q}, J_{\mathrm{HF}}=7.3\right.$ $\mathrm{Hz}, \mathrm{COF}, 1 \mathrm{~F})^{63}$

Benzoic Anhydride. The benzoyl product was formed using the general method (section 1.4.1 of the Supporting Information). Benzoic anhydride $(13 \mathrm{mg}, 0.056 \mathrm{mmol}$ ) was added to a Young's tap NMR tube containing 1 (3 $\mathrm{mg}, 0.0056 \mathrm{mmol})$ in dry, degassed $\mathrm{CD}_{3} \mathrm{CN}(0.5 \mathrm{~mL})$ with $\alpha, \alpha, \alpha$-trifluorotoluene $(1 \mu \mathrm{L})$ under argon. The contents of the tube were shaken, and the reaction was monitored via ${ }^{19} \mathrm{~F}$ NMR over time. ${ }^{19} \mathrm{~F}$ NMR yield versus the internal standard after $30 \mathrm{~min}: 47.7 \%$. ${ }^{1} \mathrm{H}$ NMR (400 MHz, ACN- $\left.d_{3}\right): \delta 8.01$ $\left(\mathrm{d}, J_{\mathrm{HH}}=7.5 \mathrm{~Hz}, \mathrm{C}_{6}-\mathrm{H}, 2 \mathrm{H}\right), \delta 7.56\left(\mathrm{t}, J_{\mathrm{HH}}=8.1 \mathrm{~Hz}, \mathrm{C}_{6}-\mathrm{H}, 1 \mathrm{H}\right)$, $7.46\left(\mathrm{t}, J_{\mathrm{HH}}=7.7 \mathrm{~Hz}, \mathrm{C}_{6}-\mathrm{H}, 2 \mathrm{H}\right) .{ }^{19} \mathrm{~F} \mathrm{NMR}\left(376 \mathrm{MHz}, \mathrm{ACN}-d_{3}\right): \delta$ $16.57(\mathrm{~s}, \mathrm{COF}, 1 \mathrm{~F}){ }^{6 .}$

Butyric Anhydride. The butanoyl fluoride product was formed using the general method (section 1.4.1 of the Supporting Information). Butyric anhydride (12 mg, $0.056 \mathrm{mmol})$ was added to a Young's tap NMR tube containing 1 (3 $\mathrm{mg}, 0.0056 \mathrm{mmol})$ in dry, degassed $\mathrm{CD}_{3} \mathrm{CN}(0.5 \mathrm{~mL})$ with $\alpha, \alpha, \alpha$-trifluorotoluene $(1 \mu \mathrm{L})$ under argon. The contents of the tube were shaken, and the reaction was monitored via ${ }^{19} \mathrm{~F}$ NMR over time. ${ }^{19} \mathrm{~F}$ NMR yield versus the internal standard after $20 \mathrm{~h}: 28.3 \% .{ }^{19} \mathrm{~F}$ NMR (376 MHz, ACN- $\left.d_{3}\right): \delta 43.10$ (s, COF, 1F). ${ }^{63}$

Toluoyl Chloride. The toluoyl fluoride product was formed using the general method (section 1.4.1 of the Supporting Information). Toluoyl chloride (9 $\mathrm{mg}, 0.056 \mathrm{mmol}$ ) was added to a Young's tap NMR tube containing $1(3 \mathrm{mg}, 0.0056 \mathrm{mmol})$ in dry, degassed $\mathrm{CD}_{3} \mathrm{CN}(0.5 \mathrm{~mL})$ with $\alpha, \alpha, \alpha$-trifluorotoluene $(1 \mu \mathrm{L})$ under argon. The contents of the tube were shaken, and the reaction was monitored via ${ }^{19} \mathrm{~F}$ NMR over time. ${ }^{19} \mathrm{~F}$ NMR yield versus the internal standard after $72 \mathrm{~h}: 18.0 \% .{ }^{1} \mathrm{H}$ NMR $\left(400 \mathrm{MHz}, \mathrm{ACN}-d_{3}\right): \delta 7.92(\mathrm{dt}$, $\left.J_{\mathrm{HH}}=1.9,8.2 \mathrm{~Hz}, \mathrm{C}_{6}-\mathrm{H}, 2 \mathrm{H}\right), \delta 7.33-7.30\left(\mathrm{~m}, \mathrm{C}_{6}-\mathrm{H}, 2 \mathrm{H}\right), 2.42(\mathrm{~s}$, $\mathrm{Me}, 3 \mathrm{H}) .{ }^{19} \mathrm{~F}$ NMR $\left(376 \mathrm{MHz}, \mathrm{ACN}-d_{3}\right): \delta 15.85$ (s, COF, 1F). ${ }^{65}$

Benzoyl Chloride. The benzoyl fluoride product was formed using the general method (section 1.4.1 of the Supporting Information). Benzoyl chloride $(8 \mathrm{mg}, 0.056 \mathrm{mmol})$ was added to a Young's tap NMR tube containing $1(3 \mathrm{mg}, 0.0056 \mathrm{mmol})$ in dry, degassed $\mathrm{CD}_{3} \mathrm{CN}(0.5 \mathrm{~mL})$ with $\alpha, \alpha, \alpha$-trifluorotoluene $(1 \mu \mathrm{L})$ under argon. The contents of the tube were shaken, and the reaction was monitored via ${ }^{19} \mathrm{~F}$ NMR over time. ${ }^{19} \mathrm{~F}$ NMR yield versus the internal standard after $72 \mathrm{~h}: 15.9 \% .{ }^{1} \mathrm{H}$ NMR (400 MHz, chloroform- $\left.d_{1}\right): \delta$ $7.96\left(\mathrm{~d}, J_{\mathrm{HH}}=7.5 \mathrm{~Hz}, \mathrm{C}_{6}-\mathrm{H}, 2 \mathrm{H}\right), \delta 7.56\left(\mathrm{t}, J_{\mathrm{HH}}=8.1 \mathrm{~Hz}, \mathrm{C}_{6}-\mathrm{H}\right.$, $1 \mathrm{H}), 7.43\left(\mathrm{t}, J_{\mathrm{HH}}=7.7 \mathrm{~Hz}, \mathrm{C}_{6}-\mathrm{H}, 2 \mathrm{H}\right) .{ }^{19} \mathrm{~F}$ NMR $(376 \mathrm{MHz}, \mathrm{ACN}-$ $\left.d_{3}\right): \delta 16.55(\mathrm{~s}, \mathrm{COF}, 1 \mathrm{~F}){ }^{64}$

\section{ASSOCIATED CONTENT}

\section{(s) Supporting Information}

The Supporting Information is available free of charge at https://pubs.acs.org/doi/10.1021/acs.organomet.0c00176.
Experimental procedures, characterization of all isolated compounds, copies of reported spectroscopic data, details of DFT and reaction performance data (PDF)

\section{Accession Codes}

CCDC 1977788 and 1978328 contain the supplementary crystallographic data for this paper. These data can be obtained free of charge via www.ccdc.cam.ac.uk/data_request/cif, or by emailing data_request@ccdc.cam.ac.uk, or by contacting The Cambridge Crystallographic Data Centre, 12 Union Road, Cambridge CB2 1EZ, UK; fax: +44 1223336033.

\section{AUTHOR INFORMATION}

\section{Corresponding Authors}

Graham C. Saunders - School of Science, University of Waikato, Hamilton 3240, New Zealand; Email: g.saunders@ waikato.ac.nz

Andrew C. Marr - School of Chemistry and Chemical Engineering, Queen's University Belfast, Belfast BT9 5AG, United Kingdom; 이이.org/0000-0001-6798-0582; Email: a.marr@qub.ac.uk

Peter Licence - GSK Carbon Neutral Laboratory, School of Chemistry, University of Nottingham, Nottingham NG7 2TU, United Kingdom; O orcid.org/0000-0003-2992-0153; Email: peter.licence@nottingham.ac.uk

\section{Authors}

Patrick J. Morgan - GSK Carbon Neutral Laboratory, School of Chemistry, University of Nottingham, Nottingham NG7 2TU, United Kingdom

Magnus W. D. Hanson-Heine - GSK Carbon Neutral Laboratory, School of Chemistry, University of Nottingham, Nottingham NG7 2TU, United Kingdom

Hayden P. Thomas - School of Science, University of Waikato, Hamilton 3240, New Zealand

Complete contact information is available at:

https://pubs.acs.org/10.1021/acs.organomet.0c00176

\section{Notes}

The authors declare no competing financial interest.

\section{ACKNOWLEDGMENTS}

We acknowledge the financial support provided by the EPSRC Centre for Doctoral Training for Sustainable Chemistry (EP/ L015633/1). M.W.D.H.H. thanks the University of Nottingham Green Chemicals Beacon for funding toward this research.

\section{REFERENCES}

(1) Marx, D. E.; Lees, A. J. Photochemistry of Dicarbonyl $\left(\eta^{5}-\right.$ Cyclopentadienyl) Iridium in Hydrocarbon Solutions: Kinetics and Mechanism of C-H Bond Activation. Inorg. Chem. 1988, 27 (7), $1121-1122$.

(2) O'Hagan, D. Understanding Organofluorine Chemistry. An Introduction to the C-F Bond. Chem. Soc. Rev. 2008, 37 (2), 308319.

(3) Dichiarante, V.; Milani, R.; Metrangolo, P. Natural Surfactants towards a More Sustainable Fluorine Chemistry. Green Chem. 2018, 20 (1), 13-27.

(4) Adams, D. E. C.; Halden, R. U. Fluorinated Chemicals and the Impacts of Anthropogenic Use. ACS Symp. Ser. 2010, 1048, 539-560.

(5) Lim, X. Z. Tainted Water: The Scientists Tracing Thousands of Fluorinated Chemicals in Our Environment. Nature 2019, 566 (7742), 26-29. 
(6) Mudgal, S.; De Toni, A.; Lockwood, S.; Salés, K.; Backhaus, T.; Sorensen, B. Study on the Environmental Risks of Medicinal Products, Final Report; Executive Agency for Health and Consumers, 2013.

(7) Küster, A.; Adler, N. Pharmaceuticals in the Environment: Scientific Evidence of Risks and Its Regulation. Philos. Trans. R. Soc., B 2014, 369 (1656), 20130587.

(8) Fang, X.; Pyle, J. A.; Chipperfield, M. P.; Daniel, J. S.; Park, S.; Prinn, R. G. Challenges for the Recovery of the Ozone Layer. Nat. Geosci. 2019, 12 (8), 592-596.

(9) Prakash, G. K. S.; Jog, P. V.; Batamack, P. T. D.; Olah, G. A. Taming of Fluoroform: Direct Nucleophilic Trifluoromethylation of Si, B, S, and C Centers. Science 2012, 338 (6112), 1324-1327.

(10) Tomar, P.; Braun, T.; Kemnitz, E. Photochemical Activation of $\mathrm{SF}_{6}$ by N-Heterocyclic Carbenes to Provide a Deoxyfluorinating Reagent. Chem. Commun. 2018, 54 (70), 9753-9756.

(11) Blum, O.; Frolow, F.; Milstein, D. C-F Bond Activation by Iridium(I). A Unique Process Involving $\mathrm{P}-\mathrm{C}$ Bond Cleavage, $\mathrm{P}-\mathrm{F}$ Bond Formation and Net Retention of Oxidation State. J. Chem. Soc., Chem. Commun. 1991, 0, 258-259.

(12) Klahn, A. H.; Moore, M. H.; Perutz, R. N. Intermolecular C-F and Intramolecular C-H Activation Reaction of $\left[\operatorname{Re}\left(\eta^{5}-\mathrm{C}_{5} \mathrm{Me}_{5}\right)\right.$ $\left.(\mathrm{CO})_{3}\right]$ with Hexafluorobenzene: Crystal and Molecular Structure of $\left[\operatorname{Re}\left(\eta^{6}-\mathrm{C}_{5} \mathrm{Me}_{4} \mathrm{CH}_{2}\right)(\mathrm{CO})_{2}\left(\mathrm{C}_{6} \mathrm{~F}_{5}\right)\right]$. J. Chem. Soc., Chem. Commun. 1992, 23 (23), 1699-1701.

(13) Belt, S. T.; Helliwell, M.; Jones, W. D.; Partridge, M. G.; Perutz, R. N. $\eta^{2}$-Coordination and Carbon-Fluorine Activation of Hexafluorobenzene by Cyclopentadienylrhodium and -Iridium Complexes. J. Am. Chem. Soc. 1993, 115 (4), 1429-1440.

(14) Aizenberg, M.; Milstein, D. Catalytic Activation of CarbonFluorine Bonds by a Soluble Transition Metal Complex. Science 1994, 265 (5170), 359-361.

(15) Kiplinger, J. L.; Richmond, T. G.; Osterberg, C. E. Activation of Carbon-Fluorine Bonds by Metal Complexes. Chem. Rev. 1994, 94 (2), 373-431.

(16) Ballhorn, M.; Partridge, M. G.; Perutz, R. N.; Whittlesey, M. K. Photochemical Intermolecular $\mathrm{C}-\mathrm{H}$ and $\mathrm{C}-\mathrm{F}$ Insertion of Rhodium into Pentafluoroanisole to Generate a Metallacycle; Conversion to a Cyclic Carbene Complex. Chem. Commun. 1996, 961-962.

(17) Pupo, G.; Vicini, A. C.; Ascough, D. M. H.; Ibba, F.; Christensen, K. E.; Thompson, A. L.; Brown, J. M.; Paton, R. S.; Gouverneur, V. Hydrogen Bonding Phase-Transfer Catalysis with Potassium Fluoride: Enantioselective Synthesis of $\beta$-Fluoroamines. $J$. Am. Chem. Soc. 2019, 141 (7), 2878-2883.

(18) Shen, Q.; Huang, Y.-G.; Liu, C.; Xiao, J.-C.; Chen, Q.-Y.; Guo, Y. Review of Recent Advances in C-F Bond Activation of Aliphatic Fluorides. J. Fluorine Chem. 2015, 179, 14-22.

(19) Stahl, T.; Klare, H. F. T.; Oestreich, M. Main-Group Lewis Acids for C-F Bond Activation. ACS Catal. 2013, 3 (7), 1578-1587.

(20) Hamel, J. D.; Paquin, J. F. Activation of C-F Bonds $\alpha$ to C-C Multiple Bonds. Chem. Commun. 2018, 54 (73), 10224-10239.

(21) Weaver, J.; Senaweera, S. C-F Activation and Functionalization of Perfluoro- and Polyfluoroarenes. Tetrahedron 2014, 70 (41), $7413-7428$

(22) Clot, E.; Eisenstein, O.; Jasim, N.; Macgregor, S. A.; McGrady, J. E.; Perutz, R. N. $\mathrm{C}-\mathrm{F}$ and $\mathrm{C}-\mathrm{H}$ Bond Activation of Fluorobenzenes and Fluoropyridines at Transition Metal Centers: How Fluorine Tips the Scales. Acc. Chem. Res. 2011, 44 (5), 333-348.

(23) Eisenstein, O.; Milani, J.; Perutz, R. N. Selectivity of C-H Activation and Competition between $\mathrm{C}-\mathrm{H}$ and $\mathrm{C}-\mathrm{F}$ Bond Activation at Fluorocarbons. Chem. Rev. 2017, 117 (13), 8710-8753.

(24) Unzner, T. A.; Magauer, T. Carbon-Fluorine Bond Activation for the Synthesis of Functionalized Molecules. Tetrahedron Lett. 2015, 56 (7), 877-883.

(25) Constable, D. J. C.; Dunn, P. J.; Hayler, J. D.; Humphrey, G. R.; Leazer, J. L., Jr.; Linderman, R. J.; Lorenz, K.; Manley, J.; Pearlman, B. a.; Wells, A.; Zaks, A.; Zhang, T. Y. Key Green Chemistry Research Areas: A Perspective from Pharmaceutical Manufacturers. Green Chem. 2007, 9 (5), 411-420.
(26) Bryan, M. C.; Dunn, P. J.; Entwistle, D.; Gallou, F.; Koenig, S. G.; Hayler, J. D.; Hickey, M. R.; Hughes, S.; Kopach, M. E.; Moine, G.; Richardson, P.; Roschangar, F.; Steven, A.; Weiberth, F. J. Key Green Chemistry Research Areas from a Pharmaceutical Manufacturers' Perspective Revisited. Green Chem. 2018, 20 (22), 5082-5103.

(27) Zhu, Y.; Han, J.; Wang, J.; Shibata, N.; Sodeoka, M.; Soloshonok, V. A.; Coelho, J. A. S.; Toste, F. D. Modern Approaches for Asymmetric Construction of Carbon-Fluorine Quaternary Stereogenic Centers: Synthetic Challenges and Pharmaceutical Needs. Chem. Rev. 2018, 118 (7), 3887-3964.

(28) Wang, J.; Sánchez-Roselló, M.; Aceña, J. L.; Del Pozo, C.; Sorochinsky, A. E.; Fustero, S.; Soloshonok, V. A.; Liu, H. Fluorine in Pharmaceutical Industry: Fluorine-Containing Drugs Introduced to the Market in the Last Decade (2001-2011). Chem. Rev. 2014, 114 (4), 2432-2506.

(29) Szpera, R.; Moseley, D. F. J.; Smith, L. B.; Sterling, A. J.; Gouverneur, V. The Fluorination of $\mathrm{C}-\mathrm{H}$ Bonds: Developments and Perspectives. Angew. Chem., Int. Ed. 2019, 58 (42), 14824-14848.

(30) Kuehnel, M. F.; Lentz, D.; Braun, T. Synthesis of Fluorinated Building Blocks by Transition-Metal-Mediated Hydrodefluorination Reactions. Angew. Chem., Int. Ed. 2013, 52 (12), 3328-3348.

(31) Ahrens, T.; Kohlmann, J.; Ahrens, M.; Braun, T. Functionalization of Fluorinated Molecules by Transition-Metal-Mediated C-F Bond Activation to Access Fluorinated Building Blocks. Chem. Rev. 2015, 115 (2), 931-972.

(32) Belhomme, M. C.; Besset, T.; Poisson, T.; Pannecoucke, X. Recent Progress toward the Introduction of Functionalized Difluoromethylated Building Blocks onto $\mathrm{C}\left(\mathrm{Sp}^{2}\right)$ and $\mathrm{C}(\mathrm{Sp})$ Centers. Chem. - Eur. J. 2015, 21 (37), 12836-12865.

(33) Landelle, G.; Bergeron, M.; Turcotte-Savard, M. O.; Paquin, J. F. Synthetic Approaches to Monofluoroalkenes. Chem. Soc. Rev. 2011, 40 (5), 2867-2908.

(34) Ferguson, D. M.; Malapit, C. A.; Bour, J. R.; Sanford, M. S. Palladium-Catalyzed Difluoromethylation of Aryl Chlorides and Bromides with $\mathrm{TMSCF}_{2} \mathrm{H}$. J. Org. Chem. 2019, 84 (6), 3735-3740.

(35) Cismesia, M. A.; Ryan, S. J.; Bland, D. C.; Sanford, M. S. Multiple Approaches to the in Situ Generation of Anhydrous Tetraalkylammonium Fluoride Salts for $S_{N}$ Ar Fluorination Reactions. J. Org. Chem. 2017, 82 (10), 5020-5026.

(36) Schimler, S. D.; Cismesia, M. A.; Hanley, P. S.; Froese, R. D. J.; Jansma, M. J.; Bland, D. C.; Sanford, M. S. Nucleophilic Deoxyfluorination of Phenols via Aryl Fluorosulfonate Intermediates. J. Am. Chem. Soc. 2017, 139 (4), 1452-1455.

(37) Neumann, C. N.; Ritter, T. Late-Stage Fluorination: Fancy Novelty or Useful Tool? Angew. Chem., Int. Ed. 2015, 54 (11), 32163221.

(38) Liu, X. W.; Echavarren, J.; Zarate, C.; Martin, R. Ni-Catalyzed Borylation of Aryl Fluorides via C-F Cleavage. J. Am. Chem. Soc. 2015, 137 (39), 12470-12473.

(39) Teltewskoi, M.; Panetier, J. A.; Macgregor, S. A.; Braun, T. A Highly Reactive Rhodium(I)-Boryl Complex as a Useful Tool for C-H Bond Activation and Catalytic C-F Bond Borylation. Angew. Chem., Int. Ed. 2010, 49 (23), 3947-3951.

(40) Tan, D. H.; Lin, E.; Ji, W. W.; Zeng, Y. F.; Fan, W. X.; Li, Q.; Gao, H.; Wang, H. Copper-Catalyzed Stereoselective Defluorinative Borylation and Silylation of Gem-Difluoroalkenes. Adv. Synth. Catal. 2018, 360 (5), 1032-1037.

(41) Lindup, R. J.; Marder, T. B.; Perutz, R. N.; Whitwood, A. C. Sequential $\mathrm{C}-\mathrm{F}$ Activation and Borylation of Fluoropyridines via Intermediate $\mathrm{Rh}(\mathrm{I})$ Fluoropyridyl Complexes: A Multinuclear NMR Investigation. Chem. Commun. 2007, No. 35, 3664.

(42) Wang, Y.; Wei, C.; Tang, R.; Zhan, H.; Lin, J.; Liu, Z.; Tao, W.; Fang, Z. Silver-Catalyzed Intermolecular Amination of Fluoroarenes. Org. Biomol. Chem. 2018, 16 (34), 6191-6194.

(43) Ahrens, T.; Kohlmann, J.; Ahrens, M.; Braun, T. Functionalization of Fluorinated Molecules by Transition-Metal-Mediated C-F Bond Activation to Access Fluorinated Building Blocks. Chem. Rev. 2015, 115 (2), 931-972. 
(44) Cui, B.; Jia, S.; Tokunaga, E.; Shibata, N. Defluorosilylation of Fluoroarenes and Fluoroalkanes. Nat. Commun. 2018, 9 (1), 4393.

(45) Maity, A.; Stanek, R. J.; Anderson, B. L.; Zeller, M.; Hunter, A. D.; Moore, C. E.; Rheingold, A. L.; Gray, T. G. Fluoride Complexes of Cyclometalated Iridium(III). Organometallics 2015, 34 (1), 109-120.

(46) Truscott, B. J.; Nahra, F.; Slawin, A. M. Z.; Cordes, D. B.; Nolan, S. P. Fluoride, Bifluoride and Trifluoromethyl Complexes of Iridium(I) and Rhodium(I). Chem. Commun. 2015, 51 (1), 62-65.

(47) Bourgeois, C. J.; Garratt, S. A.; Hughes, R. P.; Larichev, R. B.; Smith, J. M.; Ward, A. J.; Willemsen, S.; Zhang, D.; DiPasquale, A. G.; Zakharov, L. N.; et al. Synthesis and Structural Characterization of (Perfluoroalkyl)Fluoroiridium(III) and (Perfluoroalkyl)Methyliridium(III) Compounds. Organometallics 2006, 25 (14), 3474-3480.

(48) Ung, G.; Bertrand, G. C-F Bond Activation with an Apparently Benign Ethynyl Dithiocarbamate, and Subsequent Fluoride Transfer Reactions. Chem. - Eur. J. 2012, 18 (41), 12955-12957.

(49) Ogiwara, Y.; Hosaka, S.; Sakai, N. Benzoyl Fluorides as Fluorination Reagents: Reconstruction of Acyl Fluorides via Reversible Acyl C - F Bond Cleavage/Formation in Palladium Catalysis. Organometallics 2020, 39, 856-861.

(50) Thomas, H. P.; Marr, A. C.; Morgan, P. J.; Saunders, G. C. Tethering of Pentamethylcyclopentadienyl and N-Heterocycle Stabilized Carbene Ligands by Intramolecular 1,4-Addition to a Polyfluorophenyl Substituent. Organometallics 2018, 37 (9), 13391341.

(51) Thomas, H. P.; Wang, Y.-M.; Lorenzini, F.; Coles, S. J.; Horton, P. N.; Marr, A. C.; Saunders, G. C. Cyclometalation via CarbonFluorine Bond Activation Induced by Silver Particles. Organometallics 2017, 36 (5), 960-963.

(52) Kiplinger, J. L.; King, M. A.; Fechtenkötter, A.; Arif, A. M.; Richmond, T. G. An Investigation of Carbon-Fluorine Bond Functionalization. Versatile Reactivity of Tungsten(II) Fluoride Carbonyl Metallacycles with Alkynes. Organometallics 1996, 15 (25), 5292-5301.

(53) Atherton, M. J.; Fawcett, J.; Holloway, J. H.; Hope, E. G.; Karaçar, A.; Russell, D. R.; Saunders, G. C. Carbon-Fluorine and Hydrogen Bond Activation and Carbon-Carbon Bond Formation in $\eta^{5}$-Pentamethylcyclopentadienyl-Rhodium and -Iridium Phosphine Complexes; Crystal Structures of $\left[\mathrm{M}\left(\eta^{5}-\mathrm{C}_{5} \mathrm{Me}_{5}\right) \mathrm{Cl}\right.$ $\left.\left\{\left(\mathrm{C}_{6} \mathrm{~F}_{5}\right)_{2} \mathrm{PCH}_{2} \mathrm{CH}_{2} \mathrm{P}\left(\mathrm{C}_{6} \mathrm{~F}_{5}\right)_{2}\right\}\right]+\mathrm{BF}_{4}-(\mathrm{M}=\mathrm{Rh}$ or Ir $)$. J. Chem. Soc., Dalton Trans. 1996, 3215-3220.

(54) Procacci, B.; Blagg, R. J.; Perutz, R. N.; Rendón, N.; Whitwood, A. C. Photochemical Reactions of Fluorinated Pyridines at HalfSandwich Rhodium Complexes: Competing Pathways of Reaction. Organometallics 2014, 33 (1), 45-52.

(55) Bellabarba, R. M.; Nieuwenhuyzen, M.; Saunders, G. C. Synthesis of Rhodium Complexes of an Asymmetric $\eta^{5}, \eta^{1}, \eta^{1}$-CycloPentadienyl- Bis(Phosphine) Ligand by Regioselective Intramolecular Dehydrofluorinative C-C Coupling. Inorg. Chim. Acta 2001, 323 (12), 78-88.

(56) Bellabarba, R. M.; Saunders, G. C. Carbon-Fluorine Bond Cleavage as a Route to Hybrid Ligands. J. Fluorine Chem. 2001, 112 (1), 139-144.

(57) Bellabarba, R. M.; Nieuwenhuyzen, M.; Saunders, G. C. Intramolecular Dehydrofluorinative Coupling of the Asymmetric Diphosphine $\mathrm{Ph}_{2} \mathrm{PCH}_{2} \mathrm{CH}_{2} \mathrm{PPh}\left(\mathrm{C}_{5} \mathrm{~F}_{4} \mathrm{~N}_{4}\right)$ and Pentamethylcyclopentadienyl Ligands in a Rhodium Complex. Organometallics 2003, 22 (9), 1802-1810.

(58) Vitz, E.; Brubaker, C. H. Photoexchange of $\eta^{5}$-Cyclopentadienide Ligands in Selected Systems. J. Organomet. Chem. 1976, 104 (2), C33-C35.

(59) Guo-shuh, J.; Brubaker, C. H. Photolytic Cyclopentadienyl Ligand Exchange in Selected Systems. Inorg. Chim. Acta 1977, 25 (C), $181-184$.

(60) Foust, D. F.; Rausch, M. D. Photodegredration Studies on $\mathrm{Cp}_{2} \mathrm{TaMe}_{3}$ and Some Deuterated Analogues. J. Organomet. Chem. 1982, 226, 47-55.

(61) McGrandle, S.; Saunders, G. C. Group 9 Complexes of an NHeterocycle Carbene Bearing a Pentafluorobenzyl Substituent:
Attempted Dehydrofluorinative Coupling of Cyclopentadienyl and N-Heterocycle Carbene Ligands. J. Fluorine Chem. 2005, 126 (4), 449-453.

(62) Ma, Y.; Wang, Y.-M.; Morgan, P. J.; Jackson, R. E.; Liu, X.; Saunders, G. C.; Lorenzini, F.; Marr, A. C. Designing Effective Homogeneous Catalysis for Glycerol Valorisation: Selective Synthesis of a Value-Added Aldehyde from 1,3-Propanediol via Hydrogen Transfer Catalysed by a Highly Recyclable, Fluorinated Cp*Ir(NHC) Catalyst. Catal. Today 2018, 307, 248-259.

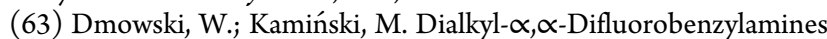
and Dialkyl(Trifluoromethyl)-Amines - Novel Fluorinating Reagents. J. Fluorine Chem. 1983, 23 (3), 219-228.

(64) Munoz, S. B.; Dang, H.; Ispizua-Rodriguez, X.; Mathew, T.; Prakash, G. K. S. Direct Access to Acyl Fluorides from Carboxylic Acids Using a Phosphine/Fluoride Deoxyfluorination Reagent System. Org. Lett. 2019, 21 (6), 1659-1663.

(65) Leclerc, M. C.; Bayne, J. M.; Lee, G. M.; Gorelsky, S. I.; Vasiliu, M.; Korobkov, I.; Harrison, D. J.; Dixon, D. A.; Baker, R. T. Perfluoroalkyl Cobalt(III) Fluoride and Bis(Perfluoroalkyl) Complexes: Catalytic Fluorination and Selective Difluorocarbene Formation. J. Am. Chem. Soc. 2015, 137 (51), 16064-16073. 